\title{
WIN OR LOSE: RESIDENTIAL SORTING AFTER A SCHOOL CHOICE LOTTERY
}

\author{
Andrew Bibler and Stephen B. Billings*
}

Abstract-We examine residential relocation and opting out of the public school system in response to school choice lottery outcomes. We show that rising kindergartners and sixth graders who lose a school choice lottery are 6 percentage points more likely to exit the district or change neighborhood schools (20\% to $30 \%$ increase) and make up 0.14 to 0.35 standard deviations in average school test scores between lottery assignment and attendance the following year. Using hedonic-based estimates of land prices, we estimate that lottery losers pay a $9 \%$ to $11 \%$ housing price premium for access to a school with a 1 standard deviation higher mean test score.

\section{Introduction}

$\mathrm{S}$ CHOOL choice has become a popular tool for public school systems to compete with the growing number of charter and private school options for families. In order to administer school choice programs, many large and diverse school districts (e.g., Boston, Charlotte, Chicago, New York, San Francisco) use lotteries to assign students to oversubscribed schools. Over the past two decades, the use of random school assignment has led to a proliferation of economics and education research that examines the impact of higher quality and specialized schools on the academic and behavioral outcomes of students. These studies find mixed evidence of winning the lottery on short-term outcomes, ${ }^{1}$ substantial benefits in long-term outcomes, ${ }^{2}$ and heterogeneity in impacts across several dimensions, including student attributes such as gender, as well as alternative measures of school quality such as school peers, teachers, and other inputs.

In spite of this sizable literature, little is known about how lottery participants reallocate housing and neighborhood consumption in response to school choice lottery outcomes. Scholars often recognize noncompliance with lottery assignment but do not explicitly examine the behavior of losers who need to compensate for lower-quality school assignment. Compensation may include moving to a neighborhood

Received for publication September 24, 2018. Revision accepted for publication March 25, 2019. Editor: Asim I. Khwaja.

*Bibler: University of Nevada, Las Vegas; Billings: University of Colorado, Boulder.

We thank seminar participants at Tulane University, University of Alaska Anchorage, University of Colorado, University of Louisville, and University of North Carolina Charlotte, as well as participants at the $2017 \mathrm{Ur}$ ban Economics Association Meetings, 2017 Association for Public Policy Analysis and Management Annual Meetings, 2018 Association for Education Finance and Policy Annual Meetings, and 2019 American Real Estate and Urban Economics Association Annual Meeting. We are grateful to the North Carolina Education Research Data Center and CharlotteMecklenburg School District for providing data.

A supplemental appendix is available online at http://www.mitpress journals.org/doi/suppl/10.1162/rest_a_00868.

${ }^{1}$ For example, end-of-grade test scores (Abdulkadiroğlu, Pathak, \& Walters, 2018; Cullen, Jacob, \& Levitt, 2006; Hoxby \& Murarka, 2009; Hastings, Kane, \& Staiger, 2006; Mills \& Wolf, 2017), and self-reported disciplinary issues (Cullen et al., 2006).

${ }^{2}$ For example, adult crime (Deming, 2011) and high school graduation and college matriculation (Deming et al., 2014). with higher assigned school quality, switching from public to private schooling, or moving to another public school district. ${ }^{3}$ The cost of this compensation is nontrivial, with private school tuition averaging over $\$ 11,000$ a year (Snyder, de Brey, \& Dillow, 2016) and homes assigned to higher-quality schools commanding price premiums that approach the cost of private schooling. ${ }^{4}$ The research presented here examines residential mobility and changes in school quality for lottery winners and losers that occur between lottery school assignment and actual school attended in the following year.

Results provide two new insights. First, we show that lottery outcomes have an impact on residential mobility and estimate the degree to which lottery losers reduce the gap in assigned school quality between winners and losers by moving to better-quality neighborhood schools. Second, we provide a new estimate of the value of school quality by examining incurred home price differentials to improve school quality. Thus, we provide an estimate of the value of school quality for a population that has strong preferences for school quality and an immediate need to purchase more school quality. This method for estimating school quality should be less sensitive to other neighborhood attributes as families have a clear need to move explicitly for access to a higher-quality residentially assigned school. Relocation choices of winners also provide insight into housing consumption reallocation after gaining access to a higher-quality school.

We use the Charlotte-Mecklenburg Schools (CMS) open enrollment program school choice lottery, which has been incorporated into a number of previous works (Hastings \& Weinstein, 2008; Hastings et al., 2005; Deming, 2011; Deming et al., 2014; Bibler, forthcoming). CMS began assigning students to oversubscribed schools through this lottery in 2002 after the end of racial-based busing. CMS is a large, urban school district, and its school choice lottery provides a number of options, including specialized magnet programs, at all levels of primary education. We limit our analysis to applicants to oversubscribed lotteries in CMS in order to compare lottery winners and losers from the same lottery across a number of outcomes. Traditionally, school lottery papers provide two types of estimates. First, one can estimate an intent-to-treat (ITT) effect of winning the lottery on various outcomes. Second, one could use lottery assignment to estimate a local average treatment effect (LATE) on various academic and behavioral outcomes for students who comply with lottery assignment. The difference between these

\footnotetext{
${ }^{3}$ Losers may also compensate in smaller ways through tutoring or parental involvement in the classroom.

${ }^{4}$ Housing price premiums for homes with good schools can be sizable based on the higher-end estimates of the value of a standard deviation improvement in school quality (upward of $10 \%$; Nguyen-Hoang \& Yinger, 2011) applied to expensive homes (over $\$ 500,000)$.
} 
two estimators includes the endogenous reaction of students to the lottery results. The fact that winners and losers have different needs to alter school quality after the lottery is the focus of our analysis.

We find that rising kindergarten and sixth-grade students who lose a school choice lottery are about 6 percentage points more likely to exit the district or change neighborhood schools, a $20 \%$ to $30 \%$ increase over baseline moving probabilities. These changes in mobility are almost entirely driven by exiting the public school system for kindergartners, but in relocating to a different neighborhood within the school district for sixth graders. Rising kindergartners and sixth graders who lost the lottery and change neighborhood schools make up between 0.22 and 0.43 standard deviations in average school test scores between lottery assignment and attendance the following year. ${ }^{5}$ Consistent with postlottery sorting based on student composition, we find that kindergarten lottery losers move to schools with a lower proportion of economically disadvantaged students and a higher proportion of white students, even after controlling for school quality. Given the link between neighborhood of residence and school assignment, sorting based on student composition may increase residential segregation more broadly. However, this sorting pattern does not hold for rising sixth-grade lottery losers, which may be consistent with weaker preferences for student composition in more experienced public school students. ${ }^{6}$ For the smaller sample of winners who move, we find limited evidence of sorting based on neighborhood home prices or moving for proximity to their first-choice school.

Our results complement previous literature on the nonmarket valuation of school quality, which estimates a $2 \%$ to $10 \%$ increase in home values for a 1 standard deviation increase in school quality (Black, 1999; Andreyeva \& Patrick, 2017; Figlio \& Lucas, 2004; Dhar \& Ross, 2012). ${ }^{7}$ We first verify that a standard boundary discontinuity estimate using our data and study area provides results in the range of the prior literature-a $7 \%$ premium in housing prices for a $1 \mathrm{SD}$ increase in school quality. ${ }^{8}$ We also show a larger premium for the highest-quality school neighborhoods. We then estimate how changes in school quality for losers and winners relate to changes in neighborhood housing prices (conditional on structural and nonschool neighborhood attributes). Using lottery losers who move, we estimate a housing price premium of $11 \%$ for kindergartners and $9 \%$ for 6 th graders for a $1 \mathrm{SD}$

\footnotetext{
${ }^{5}$ In both samples, the improvement in school quality for lottery losers who move is like going from the 25 th percentile to the median school or from the 75th percentile to a school in the 90th percentile in terms of quality.

${ }^{6}$ While sixth-grade lottery losers also move to schools with a lower proportion of economically disadvantaged students and a higher proportion of white students, the correlation is not statistically different from zero after conditioning on changes in school quality.

${ }^{7}$ This literature typically focuses on school quality measures that are based on test scores, but Clapp, Nanda, and Ross (2008) and Cellini, Ferreira, and Rothstein (2010) suggest that other school-level attributes, including demographics and infrastructure, are also capitalized in property values.

${ }^{8}$ Most of the recent literature places estimates closer to $2 \%$ to $4 \%$, but the large diversity in school quality within our study area may explain our higher estimates.
}

increase in test scores. Our large estimates for school quality using lottery losers are quite plausible for two reasons. First, lottery applicants are living in neighborhoods with average school quality to begin with; thus, increasing school quality by $1 \mathrm{SD}$ would represent moving from an average school to one of the best schools in the district. Thus, there may be a substantial premium for this level of school quality. ${ }^{9}$ Second, these estimates of the value of school quality are specifically for neighborhoods chosen by families with a strong and immediate need to improve school quality, which may generate substantial housing price premiums.

Our work also complements recent empirical evidence that households with strong preferences for school quality respond to changes in school choice through residential location decisions (Billings, Brunner, \& Ross, 2018; Brunner, Cho, \& Reback, 2012; Cullen, Long, \& Reback, 2013; Schwartz, Voicus, \& Horn, 2014). For example, Billings et al. (2018) show that households gentrify neighborhoods assigned to failing schools when they are allowed to opt out of their neighborhood school under No Child Left Behind. Cullen et al. (2013) and Cortes and Friedson (2014) find that households strategically move to neighborhoods located in lower-performing school attendance zones in order to improve their odds of qualifying for the Texas Top Ten Percent Plan. There are also a number of recent papers (Tuttle, Gleason, \& Clark, 2012; Hanushek et al., 2007; Chabrier, Cohodes, \& Oreopoulos, 2016; Baude et al., 2014) that examine the introduction and growth of charter schools and discuss residential movement of families in the presence of expanded choice due to charter schools. Together, this work provides empirical evidence of theoretical assumptions and models used in Ferreyra (2007) and Nechyba (2000) to explain residential sorting based on school quality. In our context, lottery losers have a strong incentive to relocate to improve school quality, and based on their strong preferences for school quality revealed by participating in the lottery, this work predicts residential relocation. Also consistent with these sorting models, winners may prefer moving to a lowerpriced neighborhood since they no longer have to choose their neighborhood and school simultaneously. More broadly, a better understanding of how school choice policies affect residential location decisions will provide insight into the design of school choice programs.

Our results have important and timely implications for education policy as states and cities expand and refine their school choice systems (Jordan \& Gallagher, 2015). Often, little attention is paid to lottery losers who may be incurring substantial costs to improve school quality, and thus policymakers may want to expand popular school choice options to minimize the number of families denied access to a school due to capacity constraints. Additionally, our higher estimates of the willingness to pay for school quality point to substantial heterogeneity in the value families place on school quality

\footnotetext{
${ }^{9}$ This finding is consistent with Ries and Somerville (2010), who find nonlinear impacts of school quality on property values in Vancouver.
} 
and suggest that families with strong school preference and those coming from relatively high-performing schools likely have nonlinear or larger marginal benefits from improving school quality. While our results cannot speak to the optimal distribution of school quality within a school district, they show that parents are willing to incur large costs for access to high-quality schools. Given these costs, there may be large returns to public investments that expand access to high-quality or specialized magnet school programs.

\section{Lottery}

Every student enrolled in Charlotte-Mecklenburg Schools (CMS) is assigned to a neighborhood (home) school based on geographic boundaries. ${ }^{10}$ CMS students can opt out of their neighborhood school through a centralized lottery, for which they can submit up to three program choices in order of preference. Nonguaranteed seats are assigned in three rounds. ${ }^{11}$ Only first choices are considered in the first round. If there are fewer applicants than seats available to a given program, then all of the applicants to that program will be assigned to their first choice. ${ }^{12} \mathrm{We}$ focus on oversubscribed programs because identification comes from comparing winners and losers from the same lottery. When the number of applicants is greater than the number of available seats (the choice is oversubscribed), seats are assigned quasi-randomly. Seat assignment is not completely random, because the probability of winning for a particular student depends on that person's priority group. "Priority groups" refer to sets of students who meet some prespecified criteria. Over our sample period, priorities were based on geographic location and whether the student's neighborhood school is a Title I choice school. ${ }^{13}$ We use lottery (program of application by year) fixed effects and condition on other lottery rules to exploit the fact that winners should be randomly chosen within these groups. $^{14}$

Our identification strategy relies on comparing students in the same priority groups who have different lottery outcomes. After going through all first choices, second and then

\footnotetext{
${ }^{10}$ We use the terms neighborhood school and home school interchangeably to refer to the school that the student is assigned to based on location of residence, which is the school he or she would attend unless the family opts out through the lottery, relocates, or exits the district.

${ }^{11}$ Students with an older sibling in a school are guaranteed a seat in that school by making it their first choice.

${ }^{12}$ We use the term program rather than school since students apply for specific grades as well as special magnet programs that encompass only a portion of classrooms in a school.

${ }^{13}$ Title I schools are those with a high percentage of economically disadvantaged students. A Title I school becomes a Title I choice school if it fails to meet adequate yearly progress in the same subject for two consecutive years. No Child Left Behind (NCLB) required that the district allow students assigned to Title I choice schools the opportunity to attend a nonTitle I choice school, but it does not require the district to allow students to choose the school they are offered.

${ }^{14}$ In addition to priority groups, all applicants are ordered based on randomly assigned numbers. When a choice is oversubscribed, the combination of priority groups and randomly assigned numbers determines who wins the lottery.
}

third choices are considered in a similar fashion. If a student's second or third choice filled up in a previous round, he or she remains unassigned in that round. If a student does not win any of the three choices, he or she is assigned to the neighborhood school. The lottery considers student choices in sequence, so students are most likely to win a choice by picking it first, and almost all seats are awarded in the first round. The treatment assignment variable is a dummy variable for winning first choice, which should be random after conditioning on the lottery fixed effects and rules.

The data contain up to three choices for every student in order of preference, as well as sibling placement, Title I choice placement, economic disadvantage status, and transportation zone. ${ }^{15}$ We start with the sample of all applicants without a guaranteed seat and proceed in the following way. We generate lottery fixed effects as the program-by-year combinations. We proxy for Title I choice school using whether any student from his or her neighborhood school was placed under the Title I choice option that year. In all specifications, we condition on lottery fixed effects, Title I choice school status by year, and economic disadvantage status by year.

In addition to conditioning on lottery rules, we must also consider the stated requirements for specific lottery programs. This is mainly a concern for the sixth-grade sample, for which some programs restrict access to students who meet certain requirements. These requirements are generally based on whether the student scored at grade level or higher on end-of-grade exams in the prior year. For example, students who wish to enter one of the STEM programs in sixth grade must score at grade level in reading, math, and science on his or her fifth-grade end-of-grade exams. In this case, we can check whether each student met the stated requirements for the program applied to with his or her first choice in the lottery. We restrict to students who met the requirements for their first-choice program. ${ }^{16}$ Appendix table A1 provides a breakdown of the portion of applicants who won access to an oversubscribed school by lottery application year. The average share of applicants who won their first choice in each year is about $42 \%$ for rising kindergartners and $48 \%$ for rising sixth graders over our sample period of 2009 to 2012, but there is some heterogeneity across years. The year-to-year variation in win probabilities does limit the ability of applicants (especially rising sixth graders) to accurately predict probabilities from past results.

\footnotetext{
${ }^{15} \mathrm{CMS}$ stopped reporting economic disadvantage after 2010 . For the years 2011 and 2012, we proxy for economic disadvantage at the time of application using economic disadvantage status from the North Carolina Education Research Data Center (NCERDC) data. For kindergarten students, the economic disadvantage proxy comes from their third-grade observation in NCERDC. For rising sixth-grade students, we use their lagged (fifth-grade) value for economic disadvantage.

${ }^{16}$ In some cases, we cannot view whether the student met the stated requirements. Specifically, arts schools require an audition or portfolio assessment, and leadership schools require an interview. We drop these programs from the analysis because assignment is not random, conditional on observables.
} 
Figure 1.-Number of Lottery APPLiCATIONS AND PERCENT WINNERS BY GRADE

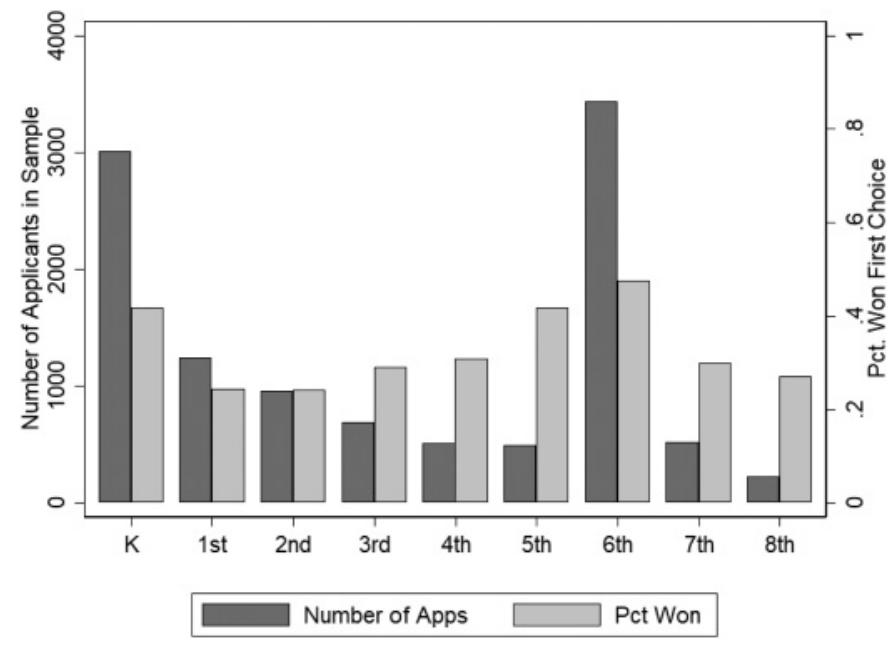

This figure provides the number of applicants and the portion of those applicants admitted to their firstchoice school for oversubscribed lotteries by grade for school years 2009 to 2012 .

\section{Data}

To examine residential movement for students who apply to a school choice lottery, we link student-level data from the lottery in CMS to data on neighborhood location and student demographics provided by the North Carolina Education Research Data Center (NCERDC). These data are unique in that they allow us to define residential location for students based on geographic attendance boundaries for school assignment (home school) during the lottery application time period (the year prior to kindergarten and the fifth-grade year) as well as the following year ( $\mathrm{K}$ and sixth grade). For fifth and sixth graders, we can also determine the Census Block Group (CBG) of residence. ${ }^{17}$ Therefore, we can observe any changes in residential location across neighborhoods or school assignment zones or both. The home school is the one that a student will be assigned to in the following year, unless he or she opts out through the lottery or changes residence and moves into the boundary of a different school. NCERDC linked the lottery data from CMS with statewide education data, which provides additional information on end-of-grade exam scores, third- through eighth-grade CBG of residence, and student demographic data. ${ }^{18}$

Even though we focus our analysis on rising kindergartners and sixth graders, parents may apply in other grades to fill spots in undersubscribed schools or seats left open by departing children in oversubscribed schools. As shown in figure 1 , most lottery applications are in school transition years ( $\mathrm{K}$ and sixth grade). First grade is the only nontransition grade

\footnotetext{
${ }^{17}$ We use CBG 2000 or 2010 depending on the year of observation.

${ }^{18}$ NCERDC was able to link between $93 \%$ and $97 \%$ of all observations from the CMS data in each year. Even though in previous work, Billings et al. (2018) incorporated exact student addresses, these data could not be incorporated into this study due to CMS restrictions in providing the lottery data. Additionally, all end-of-grade exams are scaled to have mean 0 and standard deviation of 1 based on statewide testing results for each grade and year.
}

generating a nontrivial number of applications. ${ }^{19}$ This occurs in part because access to certain magnet schools is more restricted in higher grades, fewer seats are available in preferred schools in later grades, and families become less likely to switch schools as students progress through a school.

Our analysis focuses on students entering kindergarten and sixth grade from the 2008-2009 through 2011-2012 school years who submitted an application for a program in the CMS school choice lottery and were linked from the CMS data to the NCERDC data. For the kindergarten lottery sample, we are limited to CMS lottery data. ${ }^{20}$ For the sixth-grade sample, we include a combination of the CMS lottery data, and the NCERDC data, which provides a richer set of covariates. We restrict our lottery sample to students who made at least one choice in the 2009-2012 lotteries, did not receive a sibling placement, and applied to a program-year for which at least one individual won and one lost the lottery. We then drop students who applied to a program at their neighborhood school, applied to a program for which they did not meet the entrance requirement, or applied to a program with subjective entrance requirements. For the sixth-grade sample, we also restrict to those with a lagged observation from the NCERDC data. Even though lottery applicants may apply to neighborhood schools outside their neighborhood, these schools often have limited excess seats available for choice. Therefore, $94 \%$ of our kindergarten and $80 \%$ of our sixth-grade sample are magnet school applications.

We also incorporate detailed data on home attributes (e.g., beds, baths, lot size, building area). CBG neighborhood attributes (e.g., median household income, population density) and information on the sale of a property (sales price, date of sale), which we use to construct neighborhood housing prices by CBG and neighborhood school attendance zones. This data set represents an extract of all the tax assessor records from Mecklenburg County from 1995 to 2015 . We later use all this information to generate an estimated average value of school quality by conditioning on all of our controls for housing and neighborhood attributes.

Table 1 summarizes outcomes for rising kindergarten and sixth-grade students in CMS with breakdowns for winners and losers in our lottery samples. There is substantial mobility among all rising kindergarten and sixth-grade CMS students, with $27 \%$ of kindergarten students moving by the following year. These mobility rates are somewhat lower for lottery applicants given by the "Won" and "Lost" column headings, which is consistent with a lottery applicant pool that is economically better off and has better-than-average

\footnotetext{
${ }^{19}$ After the analogous sample restrictions to our estimation sample, we have 1,243 first-grade applicants, of whom $32 \%$ of losers and $27 \%$ of winners moved within CMS or exited the district. The difference in mobility between winners and losers is similar in the first-grade and kindergarten samples. We do not focus on this group in our main analysis because most of the first-grade applicants ( $86 \%$ ) did not apply to an oversubscribed lottery as rising kindergartners and thus represent a different set of families.

${ }^{20}$ NCERDC data coverage is low for students in kindergarten through second grade.
} 
TABLE 1.-Kindergarten AND SiXTH-GRAdE Summary

\begin{tabular}{|c|c|c|c|c|c|c|c|}
\hline & \multirow{2}{*}{$\begin{array}{c}\text { CMS } \\
\text { (1) }\end{array}$} & \multirow{2}{*}{$\begin{array}{l}\text { Won } \\
(2)\end{array}$} & \multirow{2}{*}{$\begin{array}{l}\text { Lost } \\
\text { (3) }\end{array}$} & \multicolumn{4}{|c|}{ Won - Lost } \\
\hline & & & & (4) & (5) & (6) & (7) \\
\hline \multicolumn{8}{|l|}{ Kindergarten outcomes } \\
\hline \multirow[t]{2}{*}{ Mover (Change HS + Exit) } & 0.27 & 0.20 & 0.27 & $-0.070^{* * *}$ & $-0.068^{* * *}$ & $-0.053^{* *}$ & $-0.057^{* *}$ \\
\hline & $(0.44)$ & $(0.40)$ & $(0.44)$ & (0.019) & $(0.020)$ & $(0.020)$ & $(0.022)$ \\
\hline \multirow[t]{2}{*}{ Change HS (Stay) } & 0.20 & 0.15 & 0.18 & -0.023 & -0.022 & -0.007 & -0.007 \\
\hline & $(0.40)$ & $(0.36)$ & $(0.38)$ & (0.016) & (0.016) & (0.016) & $(0.020)$ \\
\hline \multirow[t]{2}{*}{ Attend App Year HS } & 0.55 & 0.06 & 0.40 & $-0.336^{* * *}$ & $-0.316^{* * *}$ & $-0.321^{* * * *}$ & $-0.308^{* * *}$ \\
\hline & $(0.50)$ & $(0.24)$ & $(0.49)$ & $(0.022)$ & $(0.021)$ & $(0.022)$ & $(0.020)$ \\
\hline \multirow[t]{2}{*}{ Attend First-Choice School } & 0.16 & 0.84 & 0.19 & $0.651^{* * * *}$ & $0.636^{* * *}$ & $0.642^{* * * *}$ & $0.656^{* * *}$ \\
\hline & $(0.37)$ & $(0.37)$ & $(0.39)$ & $(0.028)$ & $(0.030)$ & $(0.032)$ & $(0.023)$ \\
\hline \multirow[t]{2}{*}{ Won Any Choice } & 0.20 & 1.00 & 0.31 & $0.693^{* * *}$ & $0.686^{* * *}$ & $0.676^{* * * *}$ & $0.659^{* * *}$ \\
\hline & $(0.40)$ & $(0.00)$ & $(0.46)$ & $(0.020)$ & $(0.021)$ & $(0.020)$ & $(0.019)$ \\
\hline Observations & 26,966 & 1,254 & 1,751 & 3,005 & 3,005 & 3,005 & 1,693 \\
\hline \multicolumn{8}{|l|}{ Sixth-grade outcomes } \\
\hline \multirow[t]{2}{*}{ Mover (Change HS + Exit) } & 0.24 & 0.13 & 0.20 & $-0.069^{* * *}$ & $-0.057^{* * *}$ & $-0.060^{* * *}$ & $-0.051^{* * *}$ \\
\hline & $(0.42)$ & $(0.34)$ & $(0.40)$ & $(0.020)$ & $(0.018)$ & $(0.016)$ & $(0.017)$ \\
\hline \multirow{2}{*}{ Change HS (Stay) } & 0.14 & 0.11 & 0.17 & $-0.062^{* * *}$ & $-0.054^{* * *}$ & $-0.057^{* * * *}$ & $-0.051^{* * *}$ \\
\hline & $(0.34)$ & $(0.31)$ & $(0.37)$ & $(0.016)$ & $(0.015)$ & $(0.012)$ & $(0.015)$ \\
\hline \multirow[t]{2}{*}{ Attend App Year HS } & 0.62 & 0.05 & 0.38 & $-0.339^{* * *}$ & $-0.300^{* * *}$ & $-0.294^{* * *}$ & $-0.305^{* * *}$ \\
\hline & $(0.49)$ & $(0.21)$ & $(0.49)$ & $(0.053)$ & $(0.053)$ & $(0.051)$ & $(0.032)$ \\
\hline \multirow[t]{2}{*}{ Attend First-Choice School } & 0.12 & 0.89 & 0.31 & $0.584^{* * *}$ & $0.536^{* * * *}$ & $0.543^{\text {**** }}$ & $0.544^{* * *}$ \\
\hline & $(0.32)$ & $(0.31)$ & $(0.46)$ & $(0.054)$ & $(0.049)$ & $(0.049)$ & $(0.028)$ \\
\hline \multirow[t]{2}{*}{ Won Any Choice } & 0.14 & 1.00 & 0.29 & $0.710^{* * *}$ & $0.700^{* * *}$ & $0.695^{* * *}$ & $0.686^{* * *}$ \\
\hline & $(0.35)$ & $(0.00)$ & $(0.45)$ & $(0.016)$ & $(0.016)$ & $(0.017)$ & $(0.017)$ \\
\hline Observations & 34,686 & 1,637 & 1,798 & 3,435 & 3,435 & 3,435 & 2,540 \\
\hline Program-year FE & & & & - & $\sqrt{ }$ & $\sqrt{ }$ & - \\
\hline Program-year-neighborhood school FE & & & & - & - & - & $\sqrt{ }$ \\
\hline Neighborhood school FE & & & & - & - & $\sqrt{ }$ & - \\
\hline Other lottery controls & & & & - & $\sqrt{ }$ & $\sqrt{ }$ & $\sqrt{ }$ \\
\hline
\end{tabular}

$\mathrm{HS}=$ home school/neighborhood school. The first column includes all CMS students. Lottery fixed effects are program-by-year (columns 5 and 6 ) or program-by-year-by HS indicators (column 7). Columns 5 to 7 include controls for lottery priorities (e.g., economic disadvantage, LEP, and assigned Title I Choice HS).

housing stability. Relative to the district averages, lottery applicants are less likely to be Hispanic or economically disadvantaged and have higher end-of-grade exam scores. The prevalence of $19 \%$ of kindergarten losers attending their firstchoice school is mostly due to waitlist entry, but could also be due to losers moving to the neighborhood zone of a traditional public school or a partial magnet school (i.e., a school that admits lottery applicants and has associated geographic boundaries for residential assignment).

Table 1 also summarizes the lottery applicants by comparing the winners and losers. Columns 2 and 3 report averages for lottery winners and losers, respectively. Columns 4 through 7 test for differences in outcomes between the winners and losers. In column 4, we report unconditional differences between winners and losers, while column 5 adds lottery fixed effects (program of application by year) and controls for other variables that alter the probability of winning the lottery. ${ }^{21}$ In addition, we add home school fixed effects in column 6 to deal with any priority group that is based on

\footnotetext{
${ }^{21}$ Other lottery controls include variables to identify priority groups including economically disadvantaged status, Title I choice status of assigned neighborhood school, interaction between economic disadvantage and Title I choice status, and English second-language eligibility status. For the sixth-grade sample, we also include dummies for grade-level achievement, gifted status, and an indicator for being below grade level in reading and applying to a nonmagnet school.
}

home school or walk zone. ${ }^{22}$ Alternatively, column 7 uses lottery fixed effects that are program-by-year-by neighborhood school indicators. ${ }^{23}$

The first outcome, Mover (Change HS + Exit), is a dummy variable indicating whether a student has a different neighborhood school in the following year, which includes those who exited the school district. The first row in each panel of table 1 shows the estimates for the effect of winning the lottery on the probability of changing home schools or exiting CMS. After conditioning on lottery fixed effects (application choice-by-year of application), adding other covariates has little impact. For example, from column 5 of table 1, we estimate that kindergarten lottery winners are 6.8 percentage points less likely to exit or change neighborhood schools conditional on lottery fixed effects and controls. In column 7, which uses application-by-year-by-home school indicators as lottery fixed effects, we estimate that lottery winners in the kindergarten sample are 5.7 percentage points less likely to exit CMS or change neighborhood schools. These estimates are about $25 \%$ of the average moving probability among all winners and losers.

\footnotetext{
${ }^{22} \mathrm{Home}$ school fixed effects help control for the existence of an additional priority for students who live in close proximity to a full magnet school, as well as priorities given based on larger transportation zones within CMS.

${ }^{23}$ Because the lottery groups are more restricted in this case, and we use only lotteries with at least one winner and one loser, the number of observations falls in column 7 relative to columns 4 to 6 .
} 
The second outcome, Change HS (Stay), is a dummy variable that is equal to 1 for students who show up in the CMS data the following year with a different home school than indicated in their application year. This allows us to isolate how much of the difference in exits plus moves is due to students who move to a different neighborhood school zone within CMS. From the top panel in table 1, kindergarten lottery winners are between 0 and 2 percentage points more likely to remain in the district with a different home school, indicating that almost the entire win-lose difference in movement between lotteries comes from an increased probability of exiting for those who lost the lottery. The finding that the lottery results induce movement through district exits is consistent with students opting out of the public school system altogether to attend private schools or moving to attend more suburban school districts, which in this study area contain higher-quality schools in terms of test scores. However, the fact that winning the lottery has a much smaller impact on the probability of moving to a different home school within the school district does not limit residential sorting in reaction to lottery results. Even if winners and losers move at the same rate, they might differ in location choices based on school and neighborhood quality. This could show up as an intensive margin difference- that is, even though winners are just as likely to move, they care less about the school quality in their new neighborhood because they have lotteried out of that school in favor of their first-choice program.

Finally, the third variable in table 1, Attend App Year HS, is an indicator equal to 1 for students who attend the school that was their assigned home school prior to the initial lottery. Students are assigned a home school based on location of residence at the time of the lottery (e.g., the school year before entering kindergarten for the kindergarten sample). From table 1, about $40 \%$ of lottery losers in the sample attended their initial home school assignment. There are several ways in which students who lost the lottery end up attending a different school: students obtaining their first-choice school via a waitlist, winning a second or third choice in the lottery, or changing residence to a different home school boundary. ${ }^{24}$ In comparison, only $6 \%$ of lottery winners attend their application-year home school assignment. After conditioning on lottery fixed effects and lottery rules, we find that lottery winners are about 30 to 32 percentage points less likely to attend their application-year home school.

The comparable estimates on moving, exiting, and application-year home school attendance for the sixth-grade sample are shown in the first three rows of the bottom panel of table 1. Lottery winners in the sixth-grade sample are 5 to 6 percentage points less likely to change home school or exit the district, a similar number to that in the kindergarten

\footnotetext{
${ }^{24}$ There is also a second lottery in the district that students can apply through. However, this lottery is typically designed for students who entered the district too late to participate in the first lottery, and since most seats are assigned in the first lottery, few oversubscribed schools are still available.
}

sample. In contrast to the kindergarten sample, the estimated impact of winning the lottery on staying in the district with a different home school is almost identical to the impact on exiting plus moving - about 5 to 6 percentage points. This result indicates that the entire difference in responses to the lottery outcomes between winners and losers for the sixthgrade sample is due to students remaining in the district but changing home schools between school years. The main difference between the kindergarten and sixth-grade samples is that lottery losers in the sixth-grade sample are moving within the school district rather than exiting the school district. This sixth-grade result is inconsistent with families applying to enter a high-quality public school and opting out in favor of suburban school districts or private schools if they are unsuccessful. Sixth-grade families are already invested in the public school system and may have other children in public schools, and thus are less likely to switch to a private school or move to a suburban school district. Similar to the kindergarten sample, winning the lottery decreases the probability of attending their initial home school assignment by about 30 percentage points among the sixth-grade applicants.

Appendix tables A2 and A3 include balance tests for some baseline characteristics, and F-tests for the joint significance of student characteristics that should not alter the probability of winning the lottery. Appendix table A2 includes an $F$-test for joint significance of female, black, white, Hispanic, and whether the student made a second or third choice in the lottery on predicting the lottery outcome for the kindergarten sample. The $p$-value when using the program-by-year fixed effects is 0.47 . When using the more restrictive program-byyear-by-neighborhood school lottery fixed effects in column 7 , the $p$-value for joint significance of these variables is 0.8 . In both cases, we fail to reject the null hypothesis that student characteristics do not explain winning the lottery. In appendix table A3, we provide similar information for our sixth-grade sample, and balance tests include additional variables for lagged elementary achievement and limited English proficiency (LEP) status. The $p$-value for joint significance is around 0.8 with both the basic and more restrictive lottery fixed effects. In both samples, student attributes do not explain lottery results.

Before we formally analyze how lottery winners and losers residentially sort, we consider how initial residential location relates to the schools that families apply to in the lottery. Traveling long distances to school can be costly, and families may have to provide their own transportation. The location of students and magnet schools of varying quality at the time of application may be important in interpreting the impacts of lottery results more broadly and in thinking about families on the margin of applying to the school choice lottery. However, distance to first-choice school should have no bearing on our identification strategy since all of our results are conditional on applying to the lottery and balance results are robust to including home school fixed effects. Appendix figure A1 provides an initial check that sixth-grade winners and losers are 
similar in distance to their first-choice school. ${ }^{25}$ We see minimal differences between winners and losers in the distribution of distance from a student's first-choice school and the CBG of their residence at the time of application. Losers appear to live slightly farther away from their first-choice school, which is consistent with students willing to travel farther for higher-quality schools, which are more oversubscribed in the lottery (lower probability of winning). Appendix figures A2 and A3 confirm this empirical fact. Appendix figure A2 shows that there is no relationship between potential gains in school test scores and distance to first-choice school at the time of application for schools with high win probabilities $(\geq 0.5)$. However, appendix figure A3 shows that students are willing to travel farther to schools with higher test scores if the school is high-quality in multiple dimensions, as suggested by the low win probability $(<0.5)$. In general, these statistics show that distance matters, but many families are willing to incur travel costs for a high-quality school.

\section{Methodology}

\section{A. Lottery Outcomes, Moving, and School Quality}

In this section, we formalize our empirical strategy to directly test the role of lottery outcomes on assigned and attended school quality, moving, and housing prices in new neighborhoods. We begin our analysis by estimating the impact of winning the lottery on assigned school quality using the following specification,

$$
S_{i t}^{a s}=\alpha^{a s}+\beta^{a s} \times W_{i t}+\Gamma^{a s} \times X_{i t}+\Omega_{i}^{a s}+\varepsilon_{i t}^{a s}
$$

where $S_{i t}^{a s}$ represents the average end-of-grade math and reading exam score in the school that student $i$ was assigned to in the lottery at time $t .{ }^{26}$ The assigned school is the final assignment that the student received in the lottery. For a student who won their first choice in the lottery, $S_{i t}^{a s}$ is the average test score at that person's first-choice school. Similarly, if a student won his or her second (third) choice, the quality measure will reflect the quality of the school the student specified with his or her second (third) choice. In equation (1), $W_{i t}$ is a dummy variable equal to 1 if student $i$ won his or her first choice in the lottery, and $\Omega_{i}^{a s}$ represents program-byyear fixed effects. Let $X_{i t}$ represent a vector of student-level characteristics that influence the probability of winning the lottery, including economically disadvantaged status, assignment to a Title 1 choice school, and grade-level status in math, reading, and science for sixth-grade students, as well as student-level characteristics, including sex, race indicators, and lagged test scores for sixth-grade students. So $\hat{\beta}^{a s}$ represents the within-lottery difference in average test scores of assignment schools between winners and losers. If $\hat{\beta}^{a s}>0$,

\footnotetext{
${ }^{25} \mathrm{We}$ focus on rising sixth graders since we have more disaggregate information on residence relative to rising kindergartners.

${ }^{26}$ Assignment is made at time $t$ to a school that the student will attend in time $t+1$.
}

it means that students who won the lottery were assigned to schools with higher average test scores than the students who lost the same lotteries and represents a measurement of the assignment test score advantage of winners.

In our second specification, we replace the left-hand-side variable in equation (1) with the average test score of the school that the student actually attended in the following year, $S_{i t+1}^{a t}$. Now the analogous estimator, $\hat{\beta}^{a t}$, represents the difference in average test scores between the schools that the winners and losers actually attended or the attendance test score advantage. Similar to $\hat{\beta}^{a s}, \hat{\beta}^{a t}>0$ indicates that lottery winners attend schools with higher average test scores than those who lost the same lotteries. We then combine the two measures of school quality to form a third measure of interest, $\Delta S_{i}=S_{i t}^{a s}-S_{i t+1}^{a t}$, and provide estimates from the following specification,

$$
\Delta S_{i}=\alpha^{\Delta}+\beta^{\Delta} \times W_{i t}+\Gamma^{\Delta} \times X_{i t}+\Omega_{i}^{\Delta}+\varepsilon_{i t}^{\Delta},
$$

where $\Delta S_{i}$ represents the difference in the average score between the school that student $i$ was assigned at time $t$ and the school that student $i$ actually attended at time $t+1$. This will equal 0 for students who attend the school that they were initially assigned to in the lottery and will be nonzero when student $i$ attends a different school than he or she was assigned in the lottery. Nonzero values of $\Delta S_{i}$ come from some form of noncompliance with lottery assignment. For example, a student could be admitted off a waiting to his or her first-choice school or a family could alter the student's assigned neighborhood school by relocating. In such a case, if the student attends a new neighborhood school in the following year, the average assigned and attended scores will likely differ. $^{27}$

In equation (2), $\hat{\beta}^{\Delta}$ provides a measurement of the school quality that lottery losers make up between the end of the lottery assignment and the following year. If $\hat{\beta}^{\Delta}=0$, any changes in school quality between assignment and attendance for the lottery losers are offset by equivalent changes for the lottery winners. This would be true, for example, if every student complied with his or her initial assignment. In that case, the assignment and attendance advantage for winners are equivalent, and lottery losers took no action to compensate for losing the lottery by finding a way into a different school than they were initially assigned. At the other extreme, if $\hat{\beta}^{\Delta}=\hat{\beta}^{a s}$, that suggests that the assignment advantage disappears in the time between lottery assignment and school attendance in the following year. One way that this could happen is if every lottery loser attended a school with equivalent test scores as his or her first-choice school in the lottery. In that case, there would be no attendance advantage for lottery winners. When $0<\hat{\beta}^{\Delta}<\hat{\beta}^{a s}$, there is some reduction of the assignment gap between the time of assignment

\footnotetext{
${ }^{27}$ Unless the student was also assigned to his or her future neighborhood school in the initial assignment process or in the unlikely event that the assigned and attended schools are different schools but have identical average test scores.
} 
and attendance. One way that this would occur is from lottery losers attending schools with higher test scores than they were initially assigned, although it is also possible that lottery winners attend schools with lower test scores than they were initially assigned.

We expand on equations (1) and (2) by incorporating the moving decisions of lottery winners and losers. We focus on whether the students had a change in their assigned home school between the time of the lottery and the following year. We construct a dummy variable to indicate whether a student changed home schools, move $_{i}=I\left[H S_{i t} \neq H S_{i t+1}\right]$, where $H S_{i t}$ represents the home (neighborhood) school that student $i$ was assigned to in year $t .^{28} \mathrm{~A}$ change in neighborhood school between lotteries indicates changing residence because neighborhood schools are assigned based on geographic boundaries. We use the information on neighborhood school assignments to estimate versions of equation (2) that include interaction terms between move $e_{i}$ and $W_{i}$, which allows us to estimate changes separately for students who win the lottery and move, win the lottery and stay, lose the lottery and move, and lose the lottery and stay. ${ }^{29}$ Winners who comply with their assignment and so have $\Delta \widetilde{S}_{i}=0$ are the reference group in our moving analysis. However, we still provide estimates for winners who do not comply with their lottery assignment.

\section{B. Lottery Outcomes, Moving, and Housing Prices}

After considering the changes in assigned and attended school quality between lottery winners and losers, and movers and stayers, we consider differences in housing prices by home school zones. We focus on making analogous comparisons to the school quality results. That is, we estimate changes in housing prices for lottery winners and losers who move after the lottery. The analysis and results are slightly different in the case of housing prices, because we care about capitalized school quality, which would be reflected only in the home price of neighborhoods that have guaranteed access to a school—namely, a resident's home school. Therefore, we focus on neighborhood school boundaries for home schools that students are geographically assigned to even if the student attends another school. For the purpose of computing average neighborhood housing prices, we focus on the neighborhood school assignments in the year that a student applies for the kindergarten/sixth-grade lottery and the following year after the student begins school. We begin by estimating hedonic housing price regressions for home sales in the county,

$$
\operatorname{Ln}\left(P_{h s t}\right)=\beta \times X_{h s t}+\alpha \times N_{h s t}+\delta_{t}+\varepsilon_{h s t},
$$

\footnotetext{
${ }^{28}$ Home school assignments in the lottery data in year $t$ refer to the home school that the student is assigned to for year $t+1$, based on location of current residence.

${ }^{29}$ For this analysis, we use $\Delta \widetilde{S}_{i}=S_{i t+1}^{a t}-S_{i t}^{a s}$ as the outcome, which reverses the difference from equation (2). Since the focus is on the lottery losers in this specification, using $\Delta \widetilde{S}_{i}$ helps to compare these estimates for lottery losers with the estimates based on equation (2).
}

where $P_{h s t}$ represents the sale price of home $h$ in home school boundary $s$ at time $t .{ }^{30} X_{h s t}$ represents characteristics of the home, including lot size, home size, age of the home, and other structural attributes. ${ }^{31} N_{h s t}$ represents controls for neighborhood attributes including CBG 2000 median household income, population density, and percent unemployed, as well as distance to the central business district (CBD), distance to the interstate, indicators for being located on a busy road and in a floodplain, and distance to a park. $\delta_{t}$ indicates fixed effects for the year by quarter of sale. We then average residuals from the housing price regression to the home school attendance zone to get a measure of the average unexplained portion of the home sales, which reflects school quality:

$$
\tilde{P}^{s}=\overline{\hat{\varepsilon}}_{s}=\frac{1}{n_{s}} \sum_{h=1}^{n_{s}} \hat{\varepsilon}_{h s t},
$$

where $\tilde{P}^{s}$ represents the average residualized price in home school boundary $s .{ }^{32}$ Let $\tilde{P}_{i t}^{s}$ represent the average residualized price for the home school that student $i$ is assigned to at time $t$. In the sample of rising sixth graders, we refine the price residual calculation by averaging to the CBG-home school level, which allows us to better control for neighborhoodspecific differences. We estimate housing price residual parameters for winners and losers who move based on

$$
\begin{aligned}
\Delta \tilde{P}_{i}^{s}= & \alpha^{p}+\gamma_{\text {lost }}^{p} \times \text { move }_{i} \times\left(1-W_{i t}\right)+\gamma_{\text {won }}^{p} \times \text { move }_{i} \\
& \times W_{i t}+\Gamma^{p} \times X_{i t}+\Omega_{i}^{p}+\varepsilon_{i t+1}^{p}
\end{aligned}
$$

where $\Delta \widetilde{P}_{i}^{s}=\tilde{P}_{i t+1}^{s}-\tilde{P}_{i t}^{s}$, and $\hat{\gamma}_{\text {lost }}^{p}$ and $\hat{\gamma}_{w o n}^{p}$ are estimators for the change in the average residual sale price in the neighborhood school boundary for those who moved after losing and winning the lottery, respectively. Since we are using changes in home school assignment to determine movers, the neighborhood school residual prices vary only for students who move. Estimates of $\gamma_{\text {lost }}^{p}$ and $\gamma_{\text {won }}^{p}$ based on equation (5) are relative to nonmovers, for whom the change between old and new neighborhood average residual prices is 0 by construction.

Estimates based on equation (5) tell us about changes in home price residuals but do not directly link the price differences to differences in school quality. In order to estimate the housing premium directly in terms of school quality, we interact the observed changes in home price residuals with changes in school quality. This is effectively a slight extension of equation (5) but allows us to interpret the premium

\footnotetext{
${ }^{30}$ In equation (3), $t$ refers to the quarter-year of property sale. Only in estimating this housing price hedonic model do we use subscript $t$ to refer to quarter-year of sale. All other models are limited to annual observations and thus use $t$ to refer to year.

${ }^{31} \mathrm{We}$ include a series of dummies for different structural attributes of a home, including foundation, heating, air-conditioning, home style, plumbing, and electrical.

${ }^{32}$ In our analysis, we use a value of $\tilde{P}^{s}$ that is fixed over time and represents average school quality from 2007 to 2013 .
} 
TABLe 2.-LotTery Outcomes AND School Quality

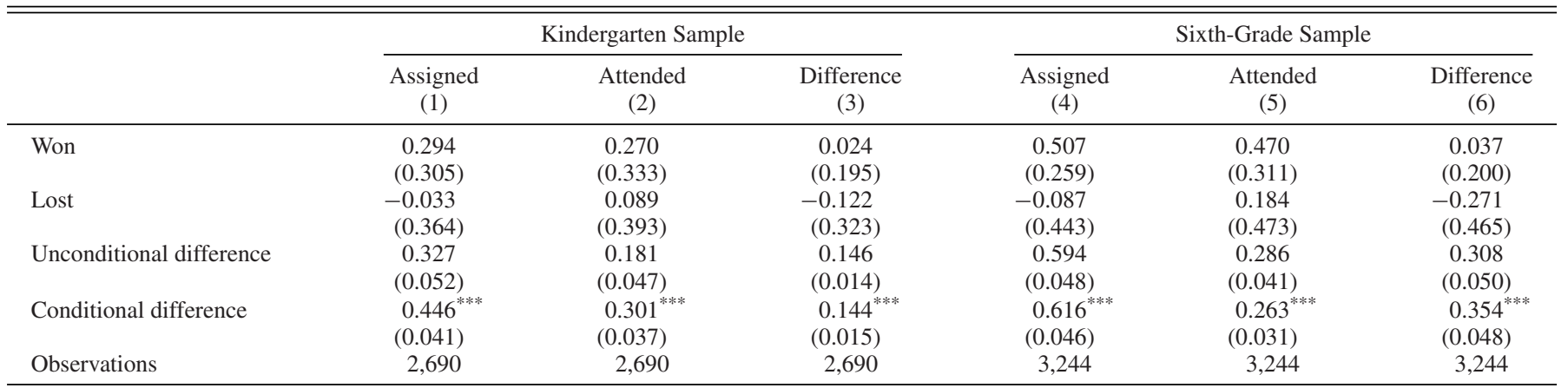

This table reports unconditional means for assigned and attended school scores, unconditional differences in scores, and the conditional difference in scores between winners and losers. "Conditional differences" are coefficients from regressions of school quality measures on winning the lottery. The dependent variable is either the average test score at the school the student was assigned in the lottery (columns 1 and 4), the average test score at the school the student was attending at the time of the lottery the following year (columns 2 and 5), or the difference in average test scores (assigned - attended) between the school the student was assigned and attended (columns 3 and 6). Rows labeled "Won" display unconditional means for winners. Rows labeled "Lost" are unconditional means for lottery losers. Rows labeled "Unconditional difference" display unconditional means in the score difference-the difference between winning and losing. Students will have a difference of 0 if they attend the school that they were assigned to in the lottery. All conditional regressions control for lottery fixed effects, and all other lottery controls (e.g., priority groups). Lottery fixed effects are application choice-by-year indicators. Standard errors are clustered by lottery. There are 66 and 46 lotteries (program-year combinations) in the kindergarten and sixth-grade, samples, respectively.

in terms of $1 \mathrm{SD}$ improvements in average school test scores and thus provides a natural comparison with estimates based on the boundary discontinuity approach used in the previous literature.

\section{School Quality Results: Assignment to Attendance}

Table 2 highlights differences in the quality (test scores) of assigned school based on the first-round results of the school choice lottery relative to the school quality actually attended in the next school year. Differences in the assignment and attendance gaps between lottery winners and losers capture student reactions to lottery outcomes. In particular, families may move to gain access to a different neighborhood school, gain access to a different school through a waiting list or other school choice option, or simply choose not to attend the school assigned in the lottery and attend their home (neighborhood) school instead. Table 2 provides two dimensions of insight. First, row values for "Won" and "Lost" provide unconditional means for average math and reading test scores for the schools that the students were assigned to and attended, as well as the difference in those two school scores. ${ }^{33}$ Columns 3 and 6 display differences in the scores of the assigned and attended schools, which highlights a small decline between assigned and attended school test scores for lottery winners but substantial improvements for losers. Second, this table highlights the conditional differences in school quality (test scores) for winners and losers from assignment to actual school attended after accounting for priority group rules in the lottery and individual-level characteristics.

A couple of elements of table 2 are interesting. First, winners are clearly assigned to schools with higher test scores,

\footnotetext{
${ }^{33}$ Differences between unconditional and conditional values are simply a result of the priority groups (e.g., economically disadvantaged, home school is Title 1 choice) that impact lottery results. As shown in appendix tables A2 and A3, winners and losers are not unconditionally balanced on student attributes, but winners and losers are balanced on observables after conditioning on lottery fixed effects and rules. Conditional means control for these priority groups and are consistent with later regression results.
}

which is consistent with the nature of the school choice lottery. The assignment difference, $\hat{\beta}^{\text {as }}$ from equation (1), is given in the "Conditional Difference" row for the assigned column and indicates an assignment advantage of 0.45 SD for kindergarten and 0.62 SD for sixth grade. ${ }^{34}$ This substantial difference between winners and losers is expected, but our analysis focuses on the changes in this difference between assignment and the actual school attended. Columns 2 and 5 provide differences between winners and losers based on test scores of actual school attended in the school year following the lottery. Differences between winners and losers are now only 0.30 and $0.26 \mathrm{SD}$ for kindergarten and sixth grade students, respectively. The large decreases are summarized in columns 3 and 6 as difference-in-differences estimates, estimates of $\beta^{\Delta}$ from equation (2), and indicate the amount of the test score assignment gap between winners and losers that is made up between initial assignment and attendance in the following year. Results show that 0.14 and 0.35 SD were made up between assignment and attendance by kindergartners and sixth graders, respectively.

Changes in school quality between assignment and attendance in table 2 are almost entirely driven by the behavior of losers. Kindergartners and sixth-grade winners attend schools of similar quality as they are assigned in the lottery, which is not surprising since $84 \%$ to $89 \%$ of lottery winners in our sample attend their first-choice school. On the other hand, the unconditional improvement in school quality of losers is about 0.12 and $0.27 \mathrm{SD}$, respectively. Even though most winners comply with lottery assignment, about $10 \%$ attend their neighborhood school or another school altogether, which explains only a small portion of the decrease in the test score gap between assignment and attendance. ${ }^{35}$ Parents may forgo their winning lottery assignment for a number of reasons. They may instead decide for their child to attend a school

\footnotetext{
${ }^{34}$ The initial assignment advantages for winners are equivalent to the difference between a median and 75 th percentile school for both kindergartners and sixth graders.

${ }^{35}$ The percentage of noncompliers is based on the proportion of winners who do not attend their first-choice school minus students who left CMS.
} 
Table 3.-Lottery Outcomes, Moving, And School Quality

\begin{tabular}{ccc}
\hline \hline & \multicolumn{2}{c}{$\begin{array}{c}\text { Attended - Assigned Score } \\
\text { (Average Test Scores) }\end{array}$} \\
\cline { 2 - 3 } & $\begin{array}{c}\text { Kindergarten } \\
(1)\end{array}$ & $\begin{array}{c}\text { Sixth Grade } \\
(2)\end{array}$ \\
\hline Lottery loser & $0.224^{* * *}$ & $0.429^{* * *}$ \\
Change HS & $(0.024)$ & $(0.031)$ \\
Same HS & $0.099^{* * *}$ & $0.294^{* * *}$ \\
Lottery winner & $(0.014)$ & $(0.053)$ \\
Noncomplier $\times$ change HS & $-0.199^{* * *}$ & $-0.582^{* * * *}$ \\
Noncomplier $\times$ same HS & $(0.064)$ & $(0.102)$ \\
Observations & $-0.199^{* *}$ & $-0.360^{* * *}$ \\
& $(0.087)$ & $(0.098)$ \\
\hline
\end{tabular}

The omitted category is winners who complied with their assignment, for whom the outcome is 0 by definition. All regressions are conditional on application choice by year fixed effects and all other lottery controls. Standard errors are clustered by lottery. There are 66 and 46 lotteries (program-year combinations) in the kindergarten and sixth-grade samples, respectively.

with his or her friends, change their preferences toward a neighborhood school after obtaining more information, or encounter transportation costs or other issues in accessing the school they chose in the lottery.

\section{A. Changes in School Quality and Moving}

Table 3 follows the same intuition from table 2 but estimates differential effects for those who change neighborhoods and those who stay in the same neighborhood after lottery assignment. ${ }^{36}$ These results provide insight into the role of stayers and movers in narrowing the gap in school quality between winners and losers shown in table 2 . The results in table 3 use a dependent variable that is equal to the average test score in the attended school minus the average test score in the assigned school. Our independent variables focus on four groups: losers who move to new neighborhoods, losers who stay, winners who move to new neighborhoods and do not comply with lottery assignment, and winners who stay in their neighborhood and do not comply with lottery assignment. Outcomes for these groups are relative to a group that has no difference between attended and assigned school: winners who comply with their assignment. If residential relocation to improve school quality is the main driver of the results in table 2 , then moving should be correlated with gains in school quality from lottery assignment to actual school attended.

Results for kindergarten in column 1 of table 3 provide evidence that losers who move ("Change HS") are able to generate large gains in average school test scores between lottery assignment and the following year, with this group attending

\footnotetext{
${ }^{36}$ Appendix table A4 provides the sample sizes of lottery winners and losers by compliance, moving decision, and whether they enrolled in their second- or third-choice school. This breakdown is helpful for interpreting results. It also highlights that losers are 4 to 6 percentage points more likely than winners to enroll in their second- or third-choice option, which is consistent with participants using their second- and third-choice schools as alternatives to neighborhood schools.
}

schools that score 0.22 SD higher than the schools that they were assigned in the lottery. These results are larger for losing sixth graders who move, a group that gains 0.43 SD between assignment and attendance. Estimated effects for losers who do not move are about one-half to two-thirds of those who move, which is indicative of changing schools via follow-up lottery assignment, accessing a non-home school via waiting lists, or opt-out provisions based on failing schools and No Child Left Behind education policy. ${ }^{37}$

Effects are very different for lottery winners who do not comply with assignment. Kindergartners who win the lottery but don't comply with their assignment see an average decrease of 0.20 standard deviations in test scores between assignment and attendance schools, whether they change home schools between the lotteries or not. Larger negative effects for noncomplying winners are mostly a reflection of the high achievement in oversubscribed schools relative to the achievement of other public school options. Since lotteryassigned schools are high quality, attending any school but the lottery-assigned school will likely result in attending a school with lower achievement than initially assigned.

The magnitude of the decrease in quality for noncomplying winners in the sixth-grade sample is more substantial. Among winners who stay in the same neighborhood school zone but forgo their lottery assignment, the estimated decrease in school test scores is $0.36 \mathrm{SD}$. This result is consistent with families applying to the lottery for the option value of attending another school. Applying for the lottery is costless, and some families may apply to magnet schools or nonneighborhood schools with limited information but decide to attend their neighborhood school after becoming more informed about the school or transportation costs. Noncomplying winners who change home schools in sixth grade have the largest decrease in school quality: $-0.58 \mathrm{SD}$. These families may be moving for nonschool reasons (e.g., rental lease expired, job opportunity) and thus may be less concerned with or not able to purchase better school quality in their new neighborhood.

Appendix tables A5 and A6 show the dimensions on which movers and stayers differ by showing summary statistics after splitting the samples of lottery winners and losers further into those who do and do not change neighborhood schools. Among both lottery winners and losers, a higher proportion of movers are black and economically disadvantaged relative to nonmovers. These results suggest that mobility may be limited by housing tenure, with families that are economically disadvantaged moving at a higher rate. The fact that a higher proportion of moving winners are economically disadvantaged relative to moving losers may represent housing reallocation for winners who have limited benefits to moving for school quality, but want to reallocate housing and

\footnotetext{
${ }^{37}$ Billings et al. (2018) show that about $30 \%$ of children are assigned to failing schools during a similar time period in CMS and about one-third of students opt out to a nonneighborhood or magnet school as allowed under NCLB.
} 
Figure 2.-Distance to Attended School: Before and After Moving

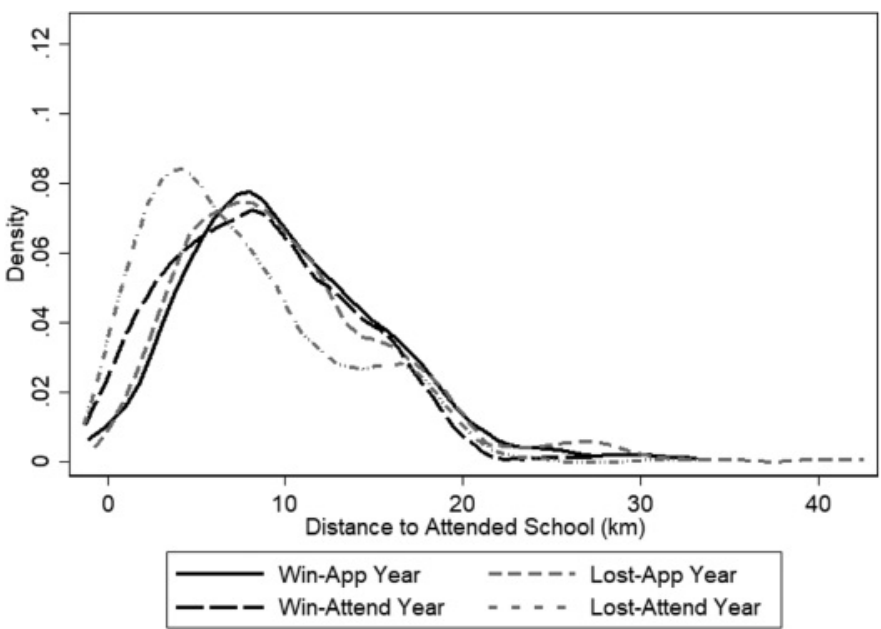

Densities of the distance $(\mathrm{km})$ between the census block group of the student's residence and the schoo attended by lottery outcome at two points in time: the year of the application and the year of attendance. Figure based on sixth-grade movers only.

neighborhood consumption. We investigate this story further in the next section.

Additionally, appendix tables A7 and A8 examine differences between compliers and noncompliers for winners and losers. These means help interpret the types of individuals who are more likely to comply with lottery assignment and thus may have different preferences or reasons for entering the lottery. Among kindergarten lottery winners, those from home schools with lower test scores and students who are black are more likely to comply with assignment. ${ }^{38}$ For sixth graders, the only difference between the student attributes of compliers and noncompliers is in home school test scores, with students from lower-scoring home schools more likely to comply if they win. Across both samples, losers who comply look similar to noncomplying losers. Together, these two tables highlight that children assigned to lower-scoring home schools are more likely to comply with winning the lottery. This result is not surprising, because the realized gains of winning the lottery are larger for applicants with lowerperforming home schools. Later results related to heterogeneity reinforce this point.

One other factor that may explain differences between movers and stayers is that movers may be relocating for proximity to the school they won admission to in the lottery. For movers, figure 2 provides evidence that lottery applicants live closer to their future attended school in the year following the lottery, and this is due to lottery losers' moving closer to the school they attend in the year following lottery application, consistent with moving to gain access to a new neighborhood school. Figure 2 also shows limited evidence that winners are moving to lower transportation costs of attending a nonneighborhood and likely farther-away school.

\footnotetext{
${ }^{38}$ Differences in means in appendix tables A7 and A8 are not exactly equal to the difference between compliers and noncompliers because we report the conditional difference in means once we control for priority groups.
}

\section{B. Heterogeneous Changes in School Quality}

We also investigate heterogeneous effects in the changes in school quality between assignment and attendance across several dimensions. Specifically, we bisect our four groups by gender, race, a dummy for economic disadvantage, home school test score terciles, and neighborhood housing price terciles in appendix tables A9 and A10. For kindergartners, we see larger school quality gains for moving lottery losers who are wealthier and white, live in low or medium schoolquality neighborhoods, and those from medium-housingprice neighborhoods. For lottery losers who stay, results are fairly consistent across groups. For noncomplying winners, we see a different pattern. Poorer, nonwhite households living in neighborhoods with lower school quality and housing prices attend schools that are considerably worse than the average noncomplying winner. These patterns are less pronounced for lottery losers in the sixth grade but consistent with noncomplying winners in kindergarten. Altogether these results suggest that lottery losers living in neighborhoods with low school-quality assignments can drastically improve school quality through residential relocation. The results for noncomplying winners highlight a greater loss in school quality for lower-income households that do not comply. Additionally, appendix tables A11 and A12 show that results are consistent across different types of magnet schools and that they are similar for schools with both lowand high-win probabilities.

Ultimately preferences over schools may depend on a number of features other than school test scores. We provide estimates for a number of alternative school-level attributes in appendix tables A13 and A14. We consider changes in school value-added, portion of students that are academically gifted, share economically disadvantaged, share designated limited English proficient, and percent of students who are white. Results highlight that alternative measures of school quality or attributes generate similar qualitative results for our groups of lottery losers and winners.

We extend this analysis further by estimating changes in percent economically disadvantaged and percent white between assignment and attendance schools for the four groups of applicants while controlling for changes in test scores in appendix tables A15 and A16. This additional analysis is informative for current policy debates about school choice lotteries and the role of lotteries in promoting or discouraging economic and racial diversity, because residential mobility in response to lottery outcomes may have an impact on the composition of schools. We provide two sets of results for each outcome. Columns 1 and 3 replicate our main analysis, replacing changes in average test scores with the two additional characteristics. Columns 2 and 4, which control for changes in school average test scores, provide the main insight. The results for kindergartners suggest that lottery losers move to schools with a lower percentage of economically disadvantaged students and a higher percentage of white students, even after controlling for school quality. We see similar 
TABle 4.-Hedonic Pricing of School Quality

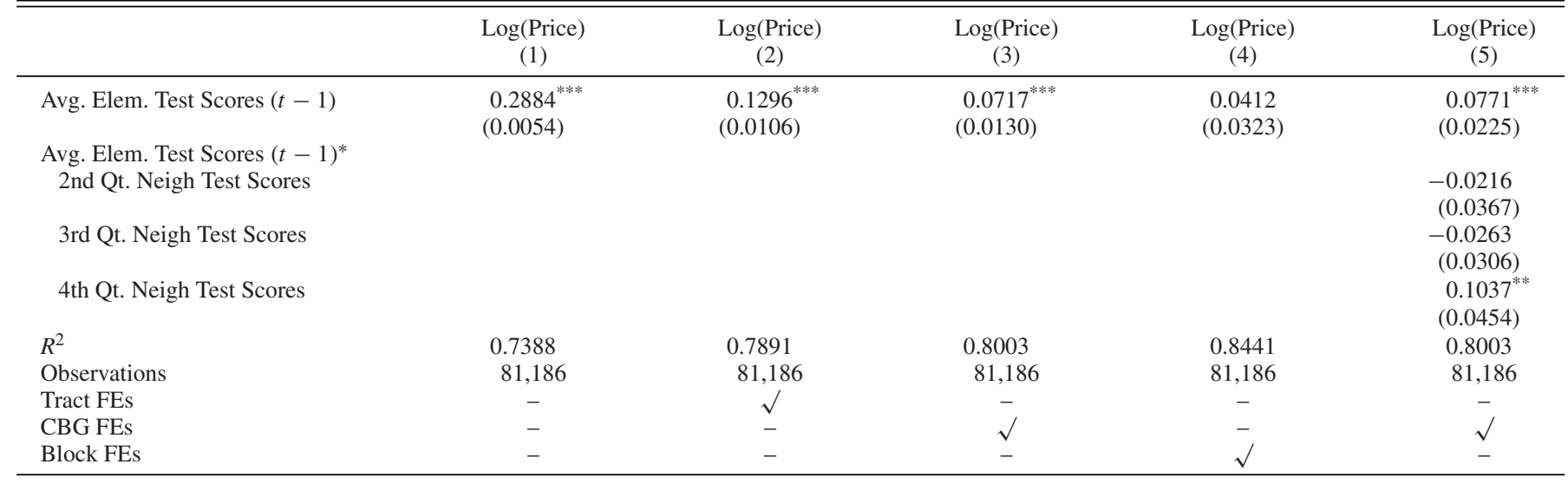

Regressions of $\log$ (price) on neighborhood school quality for Mecklenburg County home sales. Basic controls include structural attributes for age, building area, lot size, number of bathrooms, indicator for fireplace, and indicators for building material/structure types. Neighborhood controls include Census Block Group (CBG) 2000 median household income, population density, percent unemployed, indicator for floodplain, indicator for on a busy road, distance to CBG, distance to highway, and distance to park. All models include year-by-quarter fixed effects, and standard errors are clustered at the CBG level. Includes only arm's-length transactions of between $\$ 10,000$ and $\$ 1$ million for properties sold between 2007 and 2013. "Neigh" school quality quartiles based on quartiles of CBG minimum state standardized tests (mean zero, standard deviation 1).

effects for noncompliers who win. These results suggest that some of the postlottery sorting among kindergarten students may influence student composition. These results are weaker for movers in the sixth grade and may indicate less race- and income-based residential sorting for students with prior exposure to public schools. Among sixth-grade applicants, students who lose the lottery and remain in the same home school attend schools with a higher proportion of economically disadvantaged students and a lower proportion of white students than their initial assignment. However, winning sixth-grade applicants who do not move and do not comply attend schools with a lower proportion of economically disadvantaged students and a higher proportion of white students than they were initially assigned.

\section{Housing Prices and School Quality Results}

Given higher relocation rates to neighborhoods with higher-quality schools for lottery losers, we test whether housing prices reflect neighborhood school quality and then directly link changes in school quality to differences across neighborhood property values. Given the range of estimates in the literature on valuation of school quality, we first provide a hedonic-based estimate of the value of school quality using a boundary discontinuity design. Table 4 provides hedonic estimates of the impact of a 1 SD increase in one-year-lagged school average test scores on housing prices. We present estimates from four specifications with different controls for structural and neighborhood attributes. As we include progressively smaller Census 2000 geography fixed effects, our approach mimics a boundary discontinuity design by limiting identification to differences in sale prices of homes that are in the same census geography, but on opposite sides of an elementary school attendance zone that bisects that census geography. Although we provide estimates for a smaller geography, our preferred estimate includes the larger CBG fixed effects, because this is the finest level of location data that we have for the students in our sample. Our preferred estimates suggest that a $1 \mathrm{SD}$ increase in test scores generates a $7 \%$ increase in housing prices, which is in the higher range of previous estimates in other school districts. ${ }^{39}$

To examine potential nonlinearities in the valuation of school quality, in the final column of table 4 , we use the boundary discontinuity design to estimate heterogeneous valuations based on quartiles of school quality. These estimates are for the percent increase in housing prices for a $1 \mathrm{SD}$ increase in test scores for each quartile of neighborhood school quality relative to the lowest neighborhood school quality. ${ }^{40}$ The estimated valuations are similar in the bottom three quartiles, but increase to $18 \%$ for the highest-school-quality neighborhoods. The top quartile of school-quality neighborhoods contains similar test scores as the destination CBG of a number of our lottery losers.

Next, we focus on estimating the value of school quality in our sample of lottery applicants. In the first step, we average home price residuals to the neighborhood level using the sample of housing transactions in table 4 . This provides a fixed measure of neighborhood school quality across all the years of the lottery and does not account for any impacts of neighborhood prices due to our small group of lottery movers. We regress the natural log of prices on structural and neighborhood attributes, and average the residuals up to the neighborhood level. For the sample of rising kindergarten students, the elementary school attendance zone is the smallest geographical area of residence that we can place the lottery applicants in, so their assigned neighborhood price

\footnotetext{
${ }^{39}$ The literature finds a range of estimates between $2 \%$ and $10 \%$ with more recent estimates falling in the $2 \%$ to $4 \%$ range. The fact that we find a $7 \%$ premium for a $1 \mathrm{SD}$ increase in test scores is consistent with our study area, which contains a large range of school quality within the same school district. The average housing price in our sample of all single-family homes with transacted sales between 2007 and 2013 is \$226,752.

${ }^{40}$ We calculate quartiles based on the lowest average school test score for a given neighborhood, which allows discontinuities in test scores within a CBG and within each quartile.
} 
Table 5.-Lottery Outcomes, Moving, And Housing Prices

\begin{tabular}{|c|c|c|c|c|c|}
\hline & \multicolumn{5}{|c|}{$\mathrm{HS}(t+1)-\mathrm{HS}(t)$ Price Residuals } \\
\hline & $\begin{array}{c}\text { Kindergarten } \\
\text { (1) }\end{array}$ & $\begin{array}{c}\text { Kindergarten } \\
\text { (2) }\end{array}$ & $\begin{array}{l}\text { Sixth Grade } \\
\text { (3) }\end{array}$ & $\begin{array}{c}\text { Sixth Grade } \\
\text { (4) }\end{array}$ & $\begin{array}{c}\text { Sixth Grade } \\
\text { (5) }\end{array}$ \\
\hline Lost $\times$ Change HS & $\begin{array}{l}0.082^{* * *} \\
(0.021)\end{array}$ & $\begin{array}{l}0.041^{* *} \\
(0.019)\end{array}$ & $\begin{array}{l}0.080^{* * *} \\
(0.018)\end{array}$ & $\begin{array}{l}0.060^{* * *} \\
(0.015)\end{array}$ & $\begin{array}{l}0.051^{* * *} \\
(0.017)\end{array}$ \\
\hline Winners $\times$ Change HS & & & & & \\
\hline Complier & $\begin{array}{l}0.059^{* *} \\
(0.029)\end{array}$ & $\begin{array}{c}0.044^{*} \\
(0.024)\end{array}$ & $\begin{array}{c}0.054 \\
(0.042)\end{array}$ & $\begin{array}{c}0.032 \\
(0.033)\end{array}$ & $\begin{array}{c}0.058^{*} \\
(0.031)\end{array}$ \\
\hline Noncomplier & $\begin{array}{l}0.045 \\
(0.035)\end{array}$ & $\begin{array}{c}0.017 \\
(0.034)\end{array}$ & $\begin{array}{c}0.044 \\
(0.047)\end{array}$ & $\begin{array}{c}0.042 \\
(0.046)\end{array}$ & $\begin{array}{c}0.057 \\
(0.048)\end{array}$ \\
\hline Destination CBG FE & - & - & - & - & $\sqrt{ }$ \\
\hline 1st-stage Neigh controls & - & $\sqrt{ }$ & - & $\sqrt{ }$ & $\sqrt{ }$ \\
\hline Observations & 2,690 & 2,690 & 3,244 & 3,244 & 3,084 \\
\hline
\end{tabular}

All regressions include application choice-by-year fixed effects and other controls. The dependent variable is the change in the average neighborhood home price residual aggregated to either the home school level (for kindergarten sample) or home school-by-CBG level (for sixth-grade sample) for students who changed home schools between lotteries. The omitted category is all applicants who had the same home school in both the applicant and following year. The last column includes CBG fixed effects for the CBG that the student was in for the year following the lottery. The drop in observations in the final column is due to missing data on CBG and dropping singleton sets of the absorbed set of fixed effects, that is, lottery and destination CBG. Standard errors are clustered by lottery. "1st-Stage Neigh Controls" are the same as the basic and neighborhood controls used in table 3 .

residuals are at the neighborhood school zone level. For the sample of rising sixth graders, we average to the attendance zone by CBG level. ${ }^{41}$

Table 5 reports estimates of changes in neighborhood price residuals from assignment to attendance for three groups: movers who lose, movers who win and comply with lottery assignment, and winners who move but do not comply with their lottery assignment. ${ }^{42}$ The omitted group is nonmovers who by construction do not have a change in neighborhood price residuals. The first column for each sample omits neighborhood controls in the first stage, but columns 2 and 4 include these controls. For the sixth-grade sample, we further refine our estimates by conditioning on destination CBG fixed effects, and these estimates are shown in column 5 of table 5 . All groups exhibit some positive price premium relative to nonmovers, but the estimates for lottery losers are more precise and often larger than for lottery winners. Table 5 estimates show that lottery losers who move pay a $4.1 \%$ and $5.1 \%$ premium in housing prices for kindergartners and sixth graders, respectively, highlighting that movers relocate to neighborhoods with higher-quality schools. Winners who comply with assignment and move tend to relocate to neighborhoods with a smaller and less precise premium for school quality, but conclusions are somewhat limited by the small sample size of winners who move. From earlier results, winners did not appear to move closer to their attended school, and thus any incurred price premiums for winners may simply be housing consumption reallocation to nicer neighborhoods.

To test the importance of neighborhood appreciation and the bargaining power of lottery movers, we estimate different versions of table 5 in appendix tables A17 and A18 in which we focus on changes in neighborhood housing price residuals. Specifically, we use changes in residuals from the application year $(t-1)$ to attendance year $(t)$, and attendance year $(t)$ to

\footnotetext{
${ }^{41}$ NCERDC address data include the CBG of student residence, but coverage is adequate only in the sixth-grade sample.

${ }^{42}$ All estimates in table 5 use the same controls as all of our previous tables on changes in school quality.
}

the following year $(t+1)$ for a mover's destination neighborhood, as the outcomes. As shown in appendix table A17, we estimate that the neighborhoods that lottery losers move to are not appreciating at a different rate than other neighborhoods are. In appendix table A18, we estimate greater depreciation in the new neighborhoods of kindergarten lottery winners who complied with assignment in the year following the lottery. However, there are only three significant coefficients across these two tables with thirty coefficients total, which generally alleviates concerns that loser and winners are moving to different types of neighborhoods based on prior or expected appreciation. Additionally, these results provide little support that the immediate need for losers to move into a higher-school-quality neighborhood leads to a poor bargaining position and a higher transacted home price. Of course, using neighborhood price residual aggregates limits our ability to rule out this explanation, but the results suggest that the high values of school quality are more likely due to nonlinear premiums in school quality (shown in table 4) as lottery losers try and gain access to high-quality home schools.

In order to directly test whether changes in neighborhood prices map to changes in school quality, we interact the dummy variable for each group by the change in (attended - assigned) test scores. Table 6 provides results for these two groups, with the omitted group being nonmovers, and highlights the price premium for lottery losers in kindergarten and sixth grade. Estimates without controls for neighborhood quality are shown in columns 1 and 3, which estimate a relatively high value of school quality. Our preferred estimates include neighborhood controls and are shown in columns 2 and 4. Based on this specification, we estimate that lottery losers move to neighborhoods with an $11 \%$ price premium for elementary school and a $13 \%$ price premium for middle school for a 1 SD increase in test scores. For our sixth-grade sample, we include estimates from an additional specification in which we include destination CBG fixed effects. In the sixth-grade sample, the neighborhood residuals are at the CBG by school attendance zone. By including CBG 
TABle 6.-Lottery Outcomes, Moving, And Housing Prices II

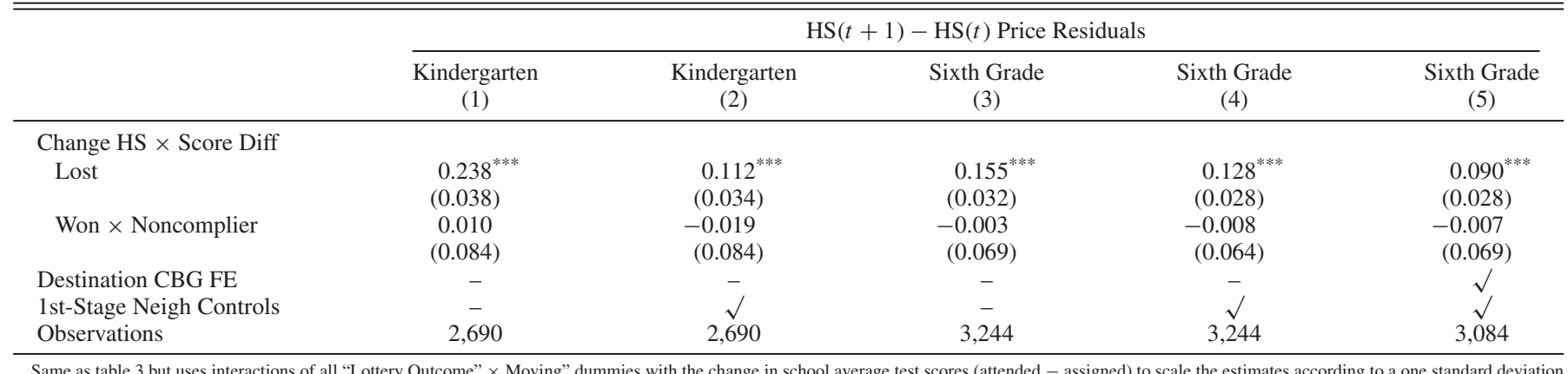
change in school quality.

fixed effects, we are identifying the school quality value estimates from the subset of destination CBGs that are bisected by school attendance zones. These estimates are shown in the last column of table 6 . We estimate that lottery losers in the sixth-grade sample move to neighborhoods that are $9 \%$ more expensive per $1 \mathrm{SD}$ increase in average test scores. In all specifications, winners who do not comply experience a noisy and near-zero relationship between incurred changes in school quality and changes in neighborhood housing prices. This result shows that changes in school quality are correlated only with changes in neighborhood housing prices for lottery losers and supports the idea that lottery winners are moving for nonneighborhood school-quality reasons.

Appendix table A19 extends the results on the kindergarten sample to examine whether estimates for the value of school quality for losers and winners who move vary by gender, race, economic disadvantage, school test score terciles, and neighborhood housing price terciles. We focus our discussion on losers since we have only a small sample of moving winners who do not comply with lottery assignment, so the related results are imprecise. In most subgroups, there is limited heterogeneity among losers, but we do estimate a larger and more precise effect for students who are wealthier (not economically disadvantaged). Turning to rising sixth graders in appendix table A20, we again find limited heterogeneity in our price effects, but do find some evidence of heterogeneous effects by school quality and average neighborhood housing price. In these two sets of terciles, we find no price effect for households moving out of more expensive and higher-quality neighborhoods based on residence at the time of lottery applications. This suggests that families with relatively good home school options are less willing to pay for access to better home schools, especially in sixth grade, with a shorter time span to realize the potential benefits of an improved home school.

Appendix tables A21 and A22 examine heterogeneity by the type of magnet school program and the probability of winning the lottery. Most effects are similar across different types of oversubscribed schools. However, there is notable heterogeneity related to how oversubscribed the lottery is: more oversubscribed $(p<0.5)$ versus less oversubscribed
( $p \geq 0.5$ ). Applicants to less oversubscribed schools generate larger estimates of the value of school quality than applicants to more oversubscribed schools. This result suggests that students who lose unexpectedly $(p \geq 0.5)$ pay a higher premium for access to a higher-quality school, which could result from a more immediate need or higher willingness to pay for an increase in quality among this group. This premium is also higher in the kindergarten sample, which is consistent with the longer potential stream of benefits from accessing a higher-quality school.

\section{Conclusion}

We examine the responses of school choice lottery losers, with a primary focus on residential relocation and opting out of the public school system in response to the results of a school choice lottery. Despite a large literature on the benefits to lottery winners, little is known about the behavior of losers who need to compensate for the lower-quality school assignment, a population that may be incurring substantial costs to improve school quality. We show that rising kindergartners and sixth-grade students who lose a school choice lottery are about 6 percentage points more likely to exit the district or change neighborhood schools, an increase of about $30 \%$ over baseline moving probabilities. Lottery losers are assigned to schools with substantially lower average performance on end-of-grade exams, but those who lost the lottery and change neighborhood schools make up 0.22 to $0.43 \mathrm{SD}$ in average school test scores between lottery assignment and attendance the following year. Using hedonic-based estimates of land prices, we estimate a housing price premium of $9 \%$ to $11 \%$ for a $1 \mathrm{SD}$ increase in school test scores.

Results provide two new insights. First, we estimate how much of the gap in school quality is made up by lottery losers through residential relocation. Second, we provide a new estimate of the value of school quality by examining incurred home price differentials for losers to improve school quality after losing the school choice lottery. Together, these findings provide insight into the potential benefits to expanding popular school choice options to minimize the number of families denied access to oversubscribed schools. Consistent 
with Hastings, Kane, and Staiger (2005), our large estimates of the value of school quality point to substantial heterogeneity in how families value school quality, suggesting that families with strong school preference and worse-performing neighborhood schools likely have nonlinear or high marginal benefits from gaining access to a high-quality school.

Given that most U.S. states now use some form of school choice (Brunner et al., 2012; Tuttle, Gleason, \& Clark, 2012), our results have some level of generalizability. The degree to which we expect our results to reflect the experience of other districts may depend on the size and composition of the population, the specifics of the school choice system, and choice options. For example, Chicago, Pittsburgh, and Raleigh are more likely to generate similar effects to Charlotte given similar student composition and focus on intradistrict school choice (Cullen et al., 2006; Engberg et al., 2014; Dur, Hammond, \& Morrill, 2018). In contrast, New Orleans and Detroit contain school lotteries and open enrollment across all schools, thereby limiting the link between school assignment and residential location (Harris \& Larsen, 2015; Glazerman \& Dotter, 2017). ${ }^{43}$ Many other school choice systems fall somewhere between these cities, with some residentialbased assignments paired with a variety of school choice options (e.g., Boston; Washington, DC; Denver). From our results, school systems with a higher concentration of lowerquality neighborhood schools and fewer economically disadvantaged applicants will generate larger residential sorting responses from lottery losers, but responses will be muted in systems with more parity in school quality and weaker links between residential location and school assignment. Regardless of school choice systems, our results highlighting large costs incurred by lottery losers to improve school quality suggest that there may be substantial returns to public investments that expand access to high-quality or specialized magnet school programs.

\footnotetext{
${ }^{43}$ Schwartz et al. (2014) provide evidence that expanded school choice leads to smaller property value effects for residentially assigned school quality.
}

\section{REFERENCES}

Abdulkadiroğlu, Atila, Parag A. Pathak, and Christopher R. Walters, "Free to Choose: Can School Choice Reduce Student Achievement?" American Economic Journal: Applied Economics 10 (2018), 175206.

Andreyeva, Elena, and Carlianne Patrick, "Paying for Priority in School Choice: Capitalization Effects of Charter School Admission Zones," Journal of Urban Economics 100 (2017), 19-32.

Baude, Patrick L., Marcus Casey, Eric A. Hanushek, Gregory R. Phelan, and Steven G. Rivkin, "The Evolution of Charter School Quality," Economica 87 (2014), 158-189.

Bibler, Andrew, "Dual Language Education and Student Achievement," Education Finance and Policy, forthcoming.

Billings, Stephen B., Eric J. Brunner, and Stephen L. Ross, "Gentrification and Failing Schools: The Unintended Consequences of School Choice under NCLB," this REVIEW 100 (2018), 65-77.

Black, Sandra E., "Do Better Schools Matter? Parental Valuation of Elementary Education," Quarterly Journal of Economics 114 (1999), $577-599$.
Brunner, Eric J., Sung-Woo Cho, and Randall Reback, "Mobility, Housing Markets, and Schools: Estimating the Effects of Inter-District Choice Programs," Journal of Public Economics 96 (2012), 604-614.

Cellini, Stephanie Riegg, Fernando Ferreira, and Jesse Rothstein, "The Value of School Facility Investments: Evidence from a Dynamic Regression Discontinuity Design," Quarterly Journal of Economics 125 (2010), 215-261.

Chabrier, Julia, Sarah Cohodes, and Philip Oreopoulos, "What Can We Learn from Charter School Lotteries?" Journal of Economic Perspectives 30 (2016), 57-84.

Clapp, John M., Anupam Nanda, and Stephen L. Ross, "Which School Attributes Matter? The Influence of School District Performance and Demographic Composition on Property Values," Journal of Urban Economics 63 (2008), 451.

Cortes, Kalena E., and Andrew I. Friedson, "Ranking Up by Moving Out: The Effect of the Texas Top 10\% Plan on Property Values," National Tax Journal 67:1 (2014), 51

Cullen, Julie Berry, Brian A. Jacob, and Steven Levitt, "The Effect of School Choice on Participants: Evidence from Randomized Lotteries," Econometrica 74 (2006), 1191-1230.

Cullen, Julie Berry, Mark C. Long, and Randall Reback, "Jockeying for Position: Strategic High School Choice under Texas' Top Ten Percent Plan," Journal of Public Economics 97 (2013), 32-48.

Deming, David J., "Better Schools, Less Crime?" Quarterly Journal of Economics 126 (2011), 2063-2115.

Deming, David J., Justine S. Hastings, Thomas J. Kane, and Douglas O. Staiger, "School Choice, School Quality, and Postsecondary Attainment," American Economic Review 104 (2014), 991-1013.

Dhar, Paramita, and Stephen L. Ross, "School District Quality and Property Values: Examining Differences along School District Boundaries,' Journal of Urban Economics 71:1 (2012), 18-25.

Dur, Umut, Robert G. Hammond, and Thayer Morrill, "Identifying the Harm of Manipulable School-Choice Mechanisms," American Economic Journal: Economic Policy 10 (2018), 187-213.

Engberg, John, Dennis Epple, Jason Imbrogno, Holger Sieg, and Ron Zimmer, "Evaluating Education Programs That Have Lotteried Admission and Selective Attrition," Journal of Labor Economics 32 (2014), $27-63$.

Ferreyra, Maria Marta, "Estimating the Effects of Private School Vouchers in Multidistrict Economies," American Economic Review 97 (2007), 789-817.

Figlio, David N., and Maurice E. Lucas, "What's in a Grade? School Report Cards and the Housing Market," American Economic Review 94 (2004), 591-604.

Glazerman, Steven, and Dallas Dotter, "Market Signals: Evidence on the Determinants and Consequences of School Choice from a Citywide Lottery," Educational Evaluation and Policy Analysis 39 (2017), 593-619.

Hanushek, Eric A., John F. Kain, Steven G. Rivkin, and Gregory F. Branch, "Charter School Quality and Parental Decision Making with School Choice," Journal of Public Economics 91 (2007), 823-848.

Harris, Douglas N., and Matthew Larsen, "What Schools Do Families Want (and Why)?" "Education Research Alliance for New Orleans," policy brief (2015).

Hastings, Justine S., Thomas J. Kane, and Douglas O. Staiger, "Parental Preferences and School Competition: Evidence from a Public School Choice Program," NBER technical report (2005).

"Preferences and Heterogeneous Treatment Effects in a Public School Choice Lottery, NBER technical report (2006).

Hastings, Justine S., and Jeffrey M. Weinstein, "Information, School Choice, and Academic Achievement: Evidence from Two Experiments," Quarterly Journal of Economics 123 (2008), 1373-1414.

Hoxby, Caroline M., and Sonali Murarka, "Charter Schools in New York City: Who Enrolls and How They Affect Their Students' Achievement," NBER technical report (2009).

Jordan, Reed, and Megan Gallagher, "Does School Choice Affect Gentrification?" in Urban Institute, Posing the Question and Assessing the Evidence (Washington, DC: Urban Institute, 2015).

Mills, Jonathan N., and Patrick J. Wolf, "Vouchers in the Bayou: The Effects of the Louisiana Scholarship Program on Student Achievement after 2 Years," Educational Evaluation and Policy Analysis 39:3 (2017), 464-484

Nechyba, Thomas J., "Mobility, Targeting, and Private-School Vouchers," American Economic Review 90 (2000), 130-146. 
Nguyen-Hoang, Phuong, and John Yinger, "The Capitalization of School Quality into House Values: A Review," Journal of Housing Economics 20 (2011), 30-48.

Ries, John, and Tsur Somerville, "School Quality and Residential Property Values: Evidence from Vancouver Rezoning," this REVIEW 92 (2010), 928-944.

Schwartz, Amy Ellen, Ioan Voicu, and Keren Mertens Horn, "Do Choice Schools Break the Link between Public Schools and Property Values? Evidence from House Prices in New York City," Regional Science and Urban Economics 49 (2014), 1-10.
Snyder, Thomas D., Cristobal de Brey, and Sally A. Dillow, Digest of Education Statistics 2014, NCES 2016-006 (Washington, DC: National Center for Education Statistics, 2016).

Tuttle, Christina Clark, Philip Gleason, and Melissa Clark, "Using Lotteries to Evaluate Schools of Choice: Evidence from a National Study of Charter Schools," Economics of Education Review 31 (2012), 237253. 